\title{
Increase in Reliability of Metal Articles with Impulse Current Effect
}

\author{
Sergey Konovalov ${ }^{1, \mathrm{a}^{*}}$, Irina Komissarova ${ }^{1, \mathrm{~b}}$, Dmitry Kosinov ${ }^{1, \mathrm{c}}$, \\ Victor Gromov ${ }^{1, \mathrm{~d}}$, Alexander Semin ${ }^{1, \mathrm{e}}$ \\ ${ }^{1}$ Siberian state industrial university, 42, Kirov Str., 654007, Novokuznetsk, Russia

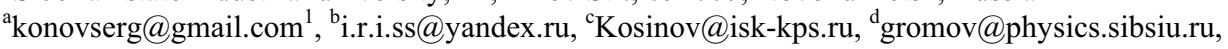 \\ 'kafspun@sibsiu.ru
}

\begin{abstract}
Investigation in duration effect of powerful electric current impulses on variation process of some properties of steels 40 and 45 and titanium alloy VT1-0 working in the high-cycle fatigue regimes was performed and nature of such an effect was detected in the research. By measuring the ultrasonic speed it was shown that electric current effect results in increase in reliability of articles.
\end{abstract}

\section{Introduction}

A lot of researches performed by the present time are devoted to the problem of fatigue. It was caused by the fact that a large number of articles work in the regimes of fatigue loads and phenomena, developing in materials under the action of repeated-variable loads pose a grave danger [1-5]. The important tests are both low-cycle fatigue tests allowing the simulation of service conditions in short time periods and high-cycle fatigue tests reflecting the process of accumulation the defects in actual articles in operation.

When speaking about articles working in regimes of fatigue loads there is no escape from touching on reliability i.e. probability that a device will successfully perform its function during a definite period of time at work in definite conditions [6]. It is possible to increase the reliability of articles working in the regimes of fatigue loads with the help of powerful electric current impulse effect. Electric current effect at a definite stage of microdefects' accumulation influences the process of microcracks development in the metals working under fatigue loads and results in changing in physical and mechanical properties of articles as well [7-9].

However, there are vaguenesses in understanding the effect of such electric current parameters as frequency and density of electric current as well as duration of electric current effect. If the parameters of electric current action are optimal then the effect of electric current processing is maximum - increase in service life of articles occurs in addition to the recovery of physical and mechanical properties $[7,10,11]$.

The purpose of the research was investigation into the effect of duration of electric current processing on the process of change in properties of steels 40, 45 and titanium alloy

* Corresponding author: konovserg@gmail.com 
VT1-0 and clarifying the nature of the effect. In this case the frequency value was fixed -20 $\mathrm{Hz}$, and current density value $-280 \mathrm{MA} / \mathrm{m}^{2}$. Measurement of ultrasonic speed [10] and X-ray diffraction method [11] being added with metallographic structural examinations were chosen as nondestructive control methods. They make possible to note the changes occurring in samples under fatigue loading and subsequent current effect.

\section{Methods and procedure of investigation}

Medium-carbon steels $40(0.4 \%$ C, $0.2 \% \mathrm{Si}, 0.7 \% \mathrm{Mn}, 0.1 \% \mathrm{Mn}, 0.015 \% \mathrm{~S}, 0.02 \% \mathrm{P}$; remainder Fe, mass. \%) and $45(0.44 \% \mathrm{C}, 0.25 \% \mathrm{Si}, 0.68 \% \mathrm{Mn}, 0.6 \% \mathrm{Mn}, 0.014 \% \mathrm{~S}, 0.022 \%$ $\mathrm{P}$; remainder Fe, mass. \%) and titanium-based alloy VT1-0 (up to $0.18 \mathrm{Fe}$; up to $0.07 \mathrm{C}$; up to $0.04 \mathrm{~N}$; up to $0.1 \mathrm{Si}$; up to $0.12 \mathrm{O}$; up to $0.004 \mathrm{H}$; 0.3 other impurities; remainder Ti, mass. \%) were tested from which articles working in regimes of fatigue loads used in machine building, instrument making and tool industries were manufactured.

The procedure of making fatigue bend tests did not differ from those described in researches $[7,10,12,13]$. Measurement of ultrasonic speed was done with setup of acoustic nondestruction control, X-ray test was done using diffractometer Shimadzu XRD-6000 in iron and copper radiation. Plotting was done in the center of stress concentrator within the following angular limits 20: 57.270 corresponding to the reflection from plane (110) - for analysis of coherent - scattering regions (CSR) and 115.50 - for analyses of macrostresses' changes - elongation stresses $\left(\sigma_{1}+\sigma_{2}\right)$ (reflection from plane (310)). Calculation of CSR and alongation stresses $\sigma_{1}+\sigma_{2}$ is done by the standard procedures. Analysis of internal macrostresses was performed against a standard - the sample in the initial state.

\section{Results and discussion}

Preliminary investigations showed that dependence of ultrasonic speed on number of loading cycles differs insignificantly from the similar dependence at low-cycle fatigue, however, in this case, this plot has a more flat view. Characteristic curve of dependence of relative ultrasonic speed change $\Delta v / v$ on number of loading cycles $\mathrm{N}$ of samples made of steel 45 is presented in Fig. 1 . The given curve has three stages. At the first stage $(\approx 20000$ loading cycles) the decrease in ultrasonic speed takes place relatively quicker but it slows down by the end. At the second stage - it is the longer and for the given steel measures $\approx$ 100000 loading cycles - speed of ultrasound propagation decreases weakly with growth of cycle number. At the concluding stage the ultrasonic speed decreases sharply. For the samples of the given steel the approach of this stage begins at their loading up to 150000 cycles. In the process of further loading after 180000 cycles macrocracks begin to form and speed of ultrasonic waves is not registered. Fracture of the samples comes at reaching 200-220 thousand cycles for a sample. 


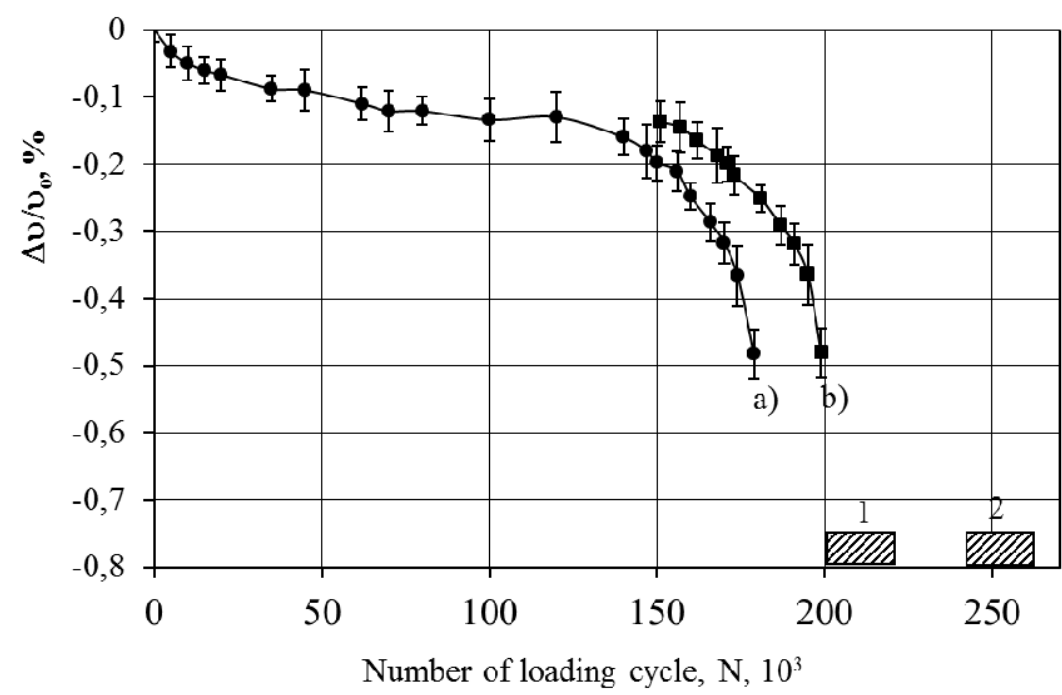

Fig.1. Dependence of relative change ultrasonic speed $\Delta v / v_{0}$ on number of loading cycles $\mathrm{N}$ for steel 45 . a) conventional loading; b) loading after current effect at $\mathrm{N}=150000$ ( $\mathrm{T}=70 \mathrm{sec}$.). 1 - region of conventional fracture, 2 - region of samples fracture processed with current.

It is evident that dependence of $v(\mathrm{~N})$ can be used in forecasting of failures that is more important for many metallic articles than statistical forecasting of failures by the definite number of failures in reliability theory. Actually, the dependence $\frac{\partial}{\partial N}\left(\frac{\Delta v}{v_{0}}\right)$ on $\mathrm{N}$ presented in Fig.2a, has a view close to the view of classical curve of failure intensity $\lambda$ against time $t-\lambda(t)$. It is seen from this curve that in the first period of work called the period of run-in the failure intensity of article is very high at the beginning and then it falls fast. In the second period (period of normal service) failure intensity fixes at a constant minimum level. In the third period (period of wear) intensity of article failure begins to rise again.

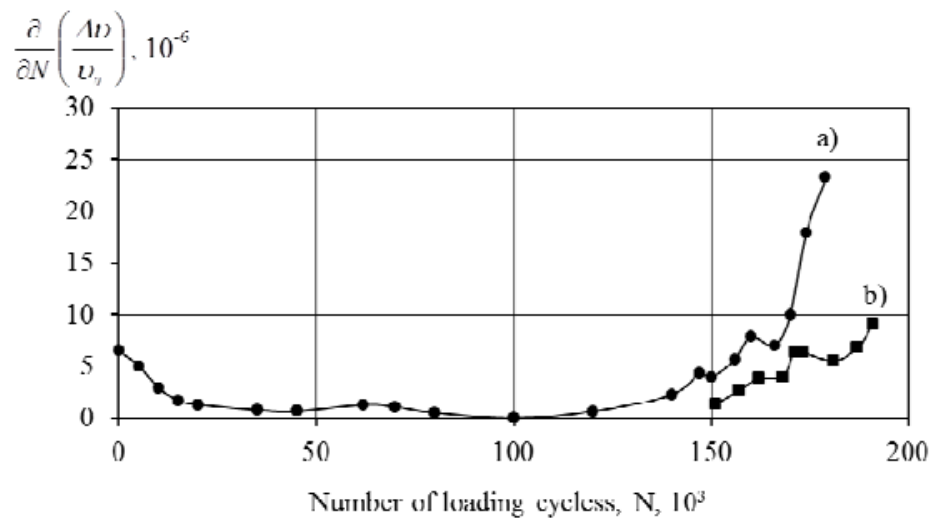

Fig.2. Dependence of relative change ultrasonic speed derivative on number of loading cycles for steel 45. a) conventional loading: b) loading after current processing at $\mathrm{N}=150000(\mathrm{t}=70 \mathrm{sec}$.). 
From the analysis of Fig.2a it follows that it is the measurement of ultrasonic speed that is the informative parameter making possible to avoid performing hundreds of destructive tests for plotting the curve $\lambda(\mathrm{t})$. Ten samples are enough to plot the curve $\frac{\partial}{\partial N}\left(\frac{\Delta v}{v_{0}}\right)$.

As the failure intensity is maximum at the third stage of dependence $\lambda(t)$ and this stage is accompanied by avalanche-like accumulation of microfractures then, evidently, it is current effect at this stage that will facilitate the most sufficient changes. Current effect at low-cycle fatigue tests at the beginning of the third stage $v(\mathrm{~N})$ results in the largest change in physical and mechanical properties being accompanied by $15-20 \%$ increase in total number of cycles that the sample resists up to failure.

That is why in our experiments the current processing was done at the third stage of dependence $v(N)$ that corresponded $\approx 75000$ cycles of loading for steel 40 , and for samples from titanium alloy VT1-0 - 130000 cycles of loading. At the given number of cycles the intensive reduction in ultrasonic speed is observed. The duration of current pulses processing was chosen 0 to $135 \mathrm{sec}$. At the further increase in duration of current effect the heating of sample exceeded $350{ }^{\circ} \mathrm{C}$

After current effect at loaded samples the ultrasonic speed in samples differed significantly from ultrasonic speed in samples in the initial state and after loading therefore the further analysis is carried out by relative dependences $\left(v_{e}-v_{n}\right) / v_{0}$, where $v_{e}-$ ultrasonic speed after current processing of the loaded samples, $v_{n}-$ ultrasonic speed after loading, $v_{0}-$ ultrasonic speed in the initial state (Fig.3). The characteristic feature of the given dependence is that at increasing the time of effect higher than 30 seconds the relative change in ultrasonic speed is statistically important. Maximum increase is established at time of effect $135 \mathrm{sec}$. and is in average $0.066 \%$.

After fatigue loading the microstresses $\left(\sigma_{1}+\sigma_{2}\right)$ according to X-ray diffraction analysis are equal to $220 \mathrm{MPa}$. In current processing during 30 seconds the abrupt decrease of stresses to value of standard sample takes place. In increase in time of electric current pulse processing to 70 seconds the increase of stresses to $300 \mathrm{MPa}$ is observed. In further increase in current effect time values $\sigma_{1}+\sigma_{2}$ are unchanged.

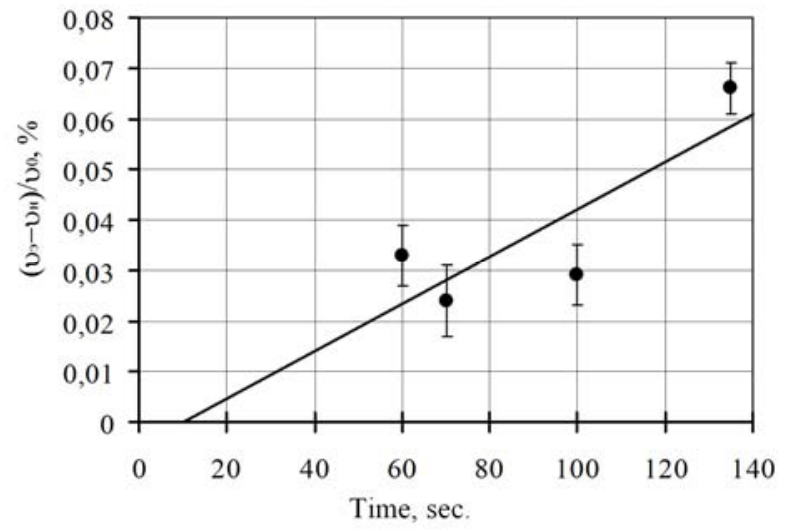

Fig.3. Dependence of relative change ultrasonic speed $\left(v_{\mathrm{e}}-v_{\mathrm{n}}\right) / v_{0}$ on current effect time at the beginning of the third stage $v(\mathrm{~N})($ steel $40, \mathrm{~N}=75000)$.

After fatigue loading the size of CSR (coherent-scattering region) measures $0.28 \mu \mathrm{m}$. The current processing during 30 seconds results in decrease in CSR size to $0.18 \mu \mathrm{m}$. In increase 
in current effect time in the interval 70 - 135 seconds the size of coherent-scattering region decreases insignificantly to $0.15 \mu \mathrm{m}$.

In performing the fatigue tests of samples processed with current it is determined that with increase in current effect time from 30 to 70 seconds the increase in fatigue life is observed. Maximum increase is observed at 70 seconds and it measures $28 \%$. In further increase in current effect time to 135 seconds the $10 \%$ decrease in fatigue life takes place. It may be suggested that up to $70 \mathrm{sec}$. time the action of mechanisms of electron-plastic effect is expressed the most clearly $[6-9,13]$, and at further time increase the thermal effect begins to prevail and may cause the fall of fatigue life.

As at optimal regimes of current effect the ultrasonic speed increases and increase in fatigue life takes place as well then it may be considered that the second stage of normal operation is prolonged (Fig.3). Actually, curve b in Fig.2 testifies that samples' respond to fatigue loading corresponds to the period of normal operation during $\approx 20000$ cycles and only after it the progressive fracture of article begins.

\section{Conclusions}

At fatigue high-cycle loading of steel 40, 45 and titanium alloy VT1-0 the dependence of ultrasonic speed on number of loading cycles presents a three-stage diminishing curve that may be compared with the curve of dependence of failure intensity on time. Relative change in ultrasonic speed of loaded samples increases linearly with current effect time in current processing at the third stage. Increase in fatigue life and prolongation of normal operation period to $28 \%$ is reached at current effect time $45-70$ seconds.

In current processing of samples during $30 \mathrm{sec}$. the reduction in elongation the stresses in the center of sample from $222 \mathrm{MPa}$ to the standard sample values takes place. With further increase of time their increase to $300 \mathrm{MPa}$ is observed. Dependence of CSR size on duration of electric stimulation decreases non-monotonously from 0.28 to $0.15 \mu \mathrm{m}$.

\section{Acknowledgement}

The work was financially supported by RFBI (project No 16-32-60048_mol_a_dk), RF President grant for state support of young Russian scientists - doctors of sciences (project No MD 2920.2015.8) and State task No 3.1496.2014/K.

\section{References}

1. H. Mughrabi, H.-J. Christ, Cyclic deformation and fatigue of selected ferritic and austenitic steels: Specific aspects, ISIJ International. 37 (1997) 1154-1169.

2. Y. Ochi, T. Sakai, Fundamentals and recent topics on fatigue III: Fatigue of metallic materials in the very high cycle regime, Zairyo/Journal of the Society of Materials Science. 52 (2003) 433-439.

3. L. Lu, W. Zhang, Review of research on very high cycle fatigue of metal materials, Jixie Qiangdu/Journal of Mechanical Strength. 27 (2005) 388-394.

4. X.Z. Chen, Y.M. Huang, Z. Shen, J. Chen, Y.C. Lei, J.Z. Zhou, Effect of thermal cycle on microstructure and mechanical properties of CLAM steel weld CGHAZ. Science and Technology of Welding and Joining. 18 (2013) 272-278. 
5. X. Chen, Y. Huang, Y. Lei, Microstructure and properties of $700 \mathrm{MPa}$ grade HSLA steel during high temperature deformation. Journal of Alloys and Compounds. 631 (2015) 225-231.

6. S.R. Calabro, Reliability Principles and Practices, McGraw Hill Book Company, Inc. New York, 1962.

7. S.V. Konovalov, A.A. Atroshkina, Yu.F. Ivanov, V.E. Gromov, Evolution of dislocation substructures in fatigue loaded and failed stainless steel with the intermediate electropulsing treatment. Materials Science and Engineering A. 527 (2010) 3040-3043.

8. H. Wang, G. Song, G. Tang, Effect of electropulsing on surface mechanical properties and microstructure of AISI 304 stainless steel during ultrasonic surface rolling process. Materials Science and Engineering A. 662 (2016) 456-467.

9. H. Wang, G. Song, G. Tang, Enhanced surface properties of austenitic stainless steel by electropulsing-assisted ultrasonic surface rolling process. Surface and Coatings Technology, 282 (2015) 149-154.

10. O.A. Sosnin, A.V. Gromova, Yu.F. Ivanov, S.V. Konovalov, V.E. Gromov, E.V. Kozlov, Control of austenite steel fatigue strength, International Journal of Fatigue. 27 (2005) 1186-1191.

11. Y. Tang, A. Hosoi, Y. Morita, Y. Ju, Restoration of fatigue damage in stainless steel by high-density electric current. International Journal of Fatigue. 56 (2013) 69-74.

12. V.E. Gromov, Yu.F. Ivanov, S.V. Vorobiev, S.V. Konovalov, Fatigue of steels modified by high intensity electron beams, Cambridge International Science Publishing Ltd, Cambridge, 2015.

13. V.A. Grishunin, V.E. Gromov, Yu.F. Ivanov, A.D. Teresov, S.V. Konovalov, Evolution of the phase composition and defect substructure of rail steel subjected to high-intensity electron-beam treatment, J. of Surf. Investigation. X-ray, Synchrotron and Neutron Techniques. 7 (2013) 990-995. 